\title{
Determination of Heavy Metals and Nutrients in Rivers Naka and Irigu, Chuka, (Kenya) Using Atomic Absorption Spectrometry and UV/Visible Spectrophotometry
}

\author{
Mutembei, J.K ${ }^{1}$; Salim, A M ${ }^{1}$; Onditi, O.A ${ }^{1}$; Waudo $\mathrm{W}^{1}$, Yusuf, A.O ${ }^{2}$. \\ ${ }^{1-}$ Jomo Kenyatta University of Agriculture and Technology, Juja Department of Chemistry, School of Physical \\ Sciences, P.O Box 62,000-00200, Nairobi. Kenya \\ ${ }^{2-}$ University of Nairobi, Department of Chemistry P.O BOX 30197-0100, Nairobi, Kenya
}

\begin{abstract}
Levels of concentration of heavy metals (lead, cadmium, arsenic and mercury) and nutrients in rivers Naka and Irigu were determined in the first three months (January, February and March, 2013) and variation downstream compared. Lead and cadmium were determined using Atomic Absorption Spectroscopy (AAS). Hydride generation method was used to determine concentration of arsenic while that of mercury was determined using cold vapour technique. Calorimetric methods were used to determine levels of nitrates and phosphates. Concentration levels of lead, cadmium and arsenic were found to be beyond the permissible levels stipulated by National Environment Management Authority (NEMA) and World Health Organisation (WHO) drinking water specifications. Lead had the highest concentration with a range of $0.0537 \pm 0.103$ parts per million (ppm) to $0.765 \pm 0.782 \mathrm{ppm}$ followed by cadmium with a concentration range of $0.035 \pm 0.006 \mathrm{ppm}$ to $0.24 \pm 0.0084 \mathrm{ppm}$ in both rivers Naka and Irigu. The high concentration levels of lead in River Naka could be attributed to disposal of wastes directly into the river from Chuka Town due to poor drainage systems. Mercury was found to be below the detection limit.

On the other hand, phosphate had a concentration range of $8.31 \pm 0.429$ ppm to $10.33 \pm 0.189$ ppm. This was above the specified level of 2.2ppm in drinking water according to NEMA. Only nitrate was below the recommended levels of 50 ppm and 45 ppm NEMA and WHO guidelines respectively for drinking water.

Keywords: Water, Heavy Metals, Nutrients, AAS, UV/Visible Spectrophotometry, River Naka, River Irigu.
\end{abstract}

\section{Introduction}

Clean water is one of mankind's most precious gifts from nature. No other public or medical innovation comes close to having the importance of a safe clean supply of drinking water [Bunce, 1994]. Water quality is important in the health and sustenance of aquatic ecosystems and hydrology. Freshwater is used for drinking, irrigation, industrial uses, production of fish, recreation, transportation and waste disposal [Jackson et al., 2001]. In addition, water plays a major role in the cycling of materials and can be a vector if it becomes [Olatunji and Osibanjo, 2012]. Water is classified as ground or surface water depending on its source. Apart from sustaining life, water is used in industries and pharmaceutical plants, mines, food processing, coolant, paper manufacturing, and so on. It is also used in agricultural irrigation and recreational purposes [Clair et al., 1978]. The quality and stability of water from rivers depends on factors like lithology of the catchment, atmospheric and anthropogenic inputs and climatic conditions [Bricker and Jones, 1995; Markich and Brown, 1998; Bellos et al., 2004; Olatunji and Osibanjo, 2012]. Heavy metals from weathered soils and rocks, mining and metallurgical releases and industrial emissions causes stress in water [Boari et al., 1997; Adams, 2001], and this may expose microflora or microfauna, aquatic lives and humans who depend on such waters to contamination [Edorh, 2007]. Even though heavy metals do not remain in water for long, water catchments areas can become a source of concern if their levels exceed the recommended levels by both local and international bodies [Salomon and Forstner, 1984]. Water has been known to be the main source of human illness, such as cholera and typhoid. Fresh water habitats, like rivers, streams, swamps, marshes and lakes contain a wide variety of microorganisms [Daniel, 1998]. Water that contains a chemical or a biological contaminants is said to be polluted. It has an unpleasant smell, taste, colour and appearance [Alcamo, 2001]. Globally, food, water and the environment are all vulnerable to low level exposure to toxic metal ions. Heavy metals are elements with a density that is greater than five times that of water. They are normally present in natural waters in trace amounts. Their toxicity is attributed to their accumulation in body tissues and competitive interference with other essential elements [Carl, 1975]. On the other hand, nutrients like phosphates and nitrates cause algal-blooms if present in excess in a water body, a condition known as eutrophication. Nitrates in drinking water are of concern due to its toxicity in young children. Rivers Naka and Irigu are surface rivers running from the slopes of Mt. Kenya Forest. They are in Meru-South District, Chuka Division. River Naka passes next to Chuka Town located on a hilly slope of Mt. Kenya. Wastes from this town drain into the river in 
form of surface run-offs. Along River Irigu are coffee factories that deposit coffee husks directly into the river. In this work, concentration levels of lead, cadmium, arsenic, mercury, nitrates and phosphates were determined in both rivers Naka and Irigu and compared. The concentration variation trend downstream was also evaluated in order to assess the suitability of the water for human consumption.

\section{Materials}

\section{Materials and Methods}

Analysis of lead and cadmium was done using Flame Atomic Absorption Spectrophotometer, Buck Scientific Model 210 VGP. HVG-1 Flame Atomic Absorption Spectrophotometer AA-62000, Buck Model Scientific 210 VGP was used to analyze arsenic, while mercury was determined using Buck Cold-Vapour Mercury Analyzer W/200A. Nutrients were analyzed using Visible Spectrophotometer. All reagents used were of analytical grade.

The study area of the two rivers is shown in the map below (Figure1)

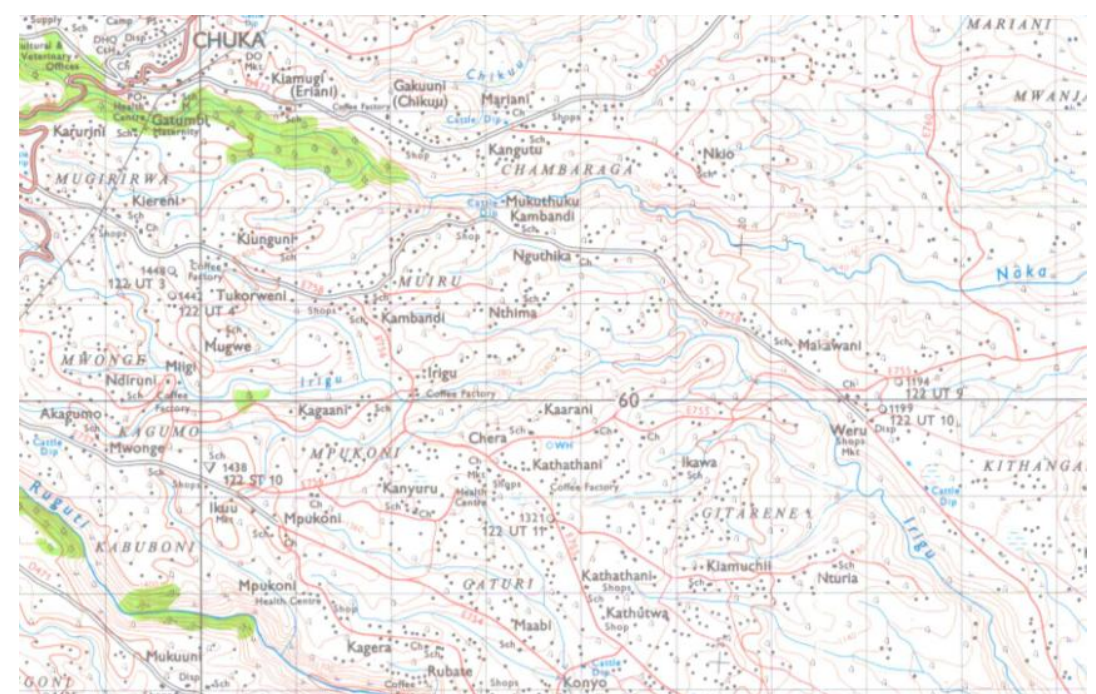

Figure 1: Map showing Rivers Naka and Irigu, in Chuka, Tharaka Nithi County

\section{Methods}

Flame atomic absorption spectrophotometer was used to determine the concentration of lead and cadmium at their respective wavelengths of $283.3 \mathrm{~nm}$ and $228.8 \mathrm{~nm}$. To increase sensitivity, hydride generation and cold vapour techniques were used in the analysis of arsenic and mercury at $193.7 \mathrm{~nm}$ and $253.7 \mathrm{~nm}$ respectively. Brucine-Sulfanilic acid was used to determine the concentration of $\mathrm{NO}_{3}{ }^{-}$spectrophotometrically at a wavelength of $410 \mathrm{~nm}$. Phosphate was determined at $660 \mathrm{~nm}$. Essential physical water parameters such as $\mathrm{pH}$, total dissolved solids, (TDS) and electrical conductivity were also determined.

Five samples from each river were collected in $500.0 \mathrm{~mL}$ plastic bottles at intervals of $1 \mathrm{~km}$ and transported in a coolant box to the university laboratory for analysis on the same day.

Physical parameters, (TDS, conductivity, $\mathrm{pH}$ ) were determined on the sampling sites using portable $\mathrm{pH}$ and TDS Meter. Two of the samples were collected on the upper part of the rivers, (with reference to Chuka Town for the case of R. Naka and coffee factory for R. Irigu) and three samples on the lower part of the rivers. $5 \mathrm{~mL}$ nitric acid at a $\mathrm{pH}$ of $2-3$ was then added to the samples and then preserved in polyethylene containers at $4^{\circ} \mathrm{C}$.

Working standards were prepared from stock solutions of 1000ppm, ( $\mathrm{Pb}, \mathrm{Cd}$, As and $\mathrm{Hg})$. To analyse nitrate, $2.0 \mathrm{~mL}$ of sample was measured into a $50.0 \mathrm{~mL}$ beaker and then $1.0 \mathrm{~mL}$ of Brucine-sulfanilic acid reagent added followed by $10.0 \mathrm{~mL}$ sulphuric acid and mixed, as described by Brandford, (1993). A yellow coloured solution was formed, whose absorbance was determined at $410 \mathrm{~nm}$. Phosphates on the other hand were analysed by adding $3.0 \mathrm{ml}$ molybdate solution to $3.0 \mathrm{~mL}$ ascorbic acid solution in a $50.0 \mathrm{~mL}$ volumetric flask and shaken well. $70.0 \mathrm{~mL}$ of sample was then added and made to the mark with distilled water, and its absorbance measured at $660 \mathrm{~nm}$.

$0.1598 \mathrm{~g}$ of lead nitrate, $\left(\mathrm{Pb}\left(\mathrm{NO}_{3}\right)_{2}\right)$ and $0.2744 \mathrm{~g}$ of cadmium nitrate, $\left(\mathrm{Cd}\left(\mathrm{NO}_{3}\right)_{2} .4 \mathrm{H}_{2} \mathrm{O}\right)$ salts were used in preparation of $1000 \mathrm{ppm}$ stock solutions of lead and cadmium respectively, by dissolving each in $100.0 \mathrm{~mL}$ of de-ionised water. Absorbencies were measured at $283.3 \mathrm{~nm}$ for lead and $228.8 \mathrm{~nm}$ for cadmium using lead and cadmium hollow cathode lamps respectively. Analysis of arsenic was done by aspirating the samples through flow injection whereby they are mixed with $\mathrm{NaBH}_{4}$ and $\mathrm{HCl}$ in the manifold and passed through a separator. 
This separated the liquid and gaseous reaction products (volatile hydrides). Starting with the blanks, standards and then samples, $2.0 \mathrm{~mL}$ of $\mathrm{KI}$ was added to $50.0 \mathrm{~mL}$ of each. The standards and samples were allowed to react completely with $0.45 \% \mathrm{NaBH}_{4}, 0.4 \% \mathrm{NaOH}$ and $5.0 \% \mathrm{HCl}$ for about 2 minutes after which absorbance was measured and recorded. Distilled water was run after every run of sample to prevent contamination. For the case of mercury, an aliquot $(50.0 \mathrm{~mL})$ of the sample was measured into the reaction flask, into which $5.0 \mathrm{~mL}$ of mixed acid solution of $\mathrm{HCl} / \mathrm{H}_{2} \mathrm{SO}_{4}$ in the ratio 3:1 was added to the vessel, and the argon flow to the bubbler started. $10 \mathrm{~g}$ of stannous chloride was added into an empty acid-cleaned $100.0 \mathrm{~mL}$ plastic bottle, and then $20.0 \mathrm{~mL}$ concentrated $\mathrm{HCl}, 2 \mathrm{~g}$ of tin and $75.0 \mathrm{~mL}$ de-ionised water added and swirled gently to dissolve. The energy was put to zero, and then slowly but steadily $5.0 \mathrm{~mL}$ stannous chloride, $\left(\mathrm{SnCl}_{2}\right)$ reductant solution was injected into the septum of the flask stopper assembly with a syringe. Signal interactions were started at this time. The reading was allowed to get back or close to zero after which the argon bubbler flow was turned off and the reaction flask removed. The flask was then rinsed with $5.0 \% \mathrm{HCl} / 5.0 \% \mathrm{H}_{2} \mathrm{O}_{2}$ and the bubbler soaked also in the same mixture to remove traces of the $\mathrm{SnCl}_{2}$.

\section{Results and Discussion}

Results

The Tables below show the results obtained for the various parameters.

Table 1: Physiochemical Parameters for River Naka

$1^{\text {st }}$ Sampling-January, 2013

\begin{tabular}{|c|c|c|c|c|c|c|c|c|c|}
\hline \multirow{2}{*}{\multicolumn{2}{|c|}{$\begin{array}{l}\text { Physiochemical } \\
\text { Parameters } \\
\end{array}$}} & \multicolumn{8}{|c|}{ Sampling stations } \\
\hline & & \multicolumn{2}{|r|}{ NU1 } & NU2 & NL3 & NL4 & \multicolumn{2}{|l|}{ NL5 } & \multirow[t]{2}{*}{ NEMA } \\
\hline pH & & 6.7 & 6.3 & 6.4 & 6.5 & 6.8 & 6.5 & -8.5 & \\
\hline $\mathrm{EC}, \mathrm{mS}$ & 0.06 & 0.06 & & 0.06 & 0.06 & 0.07 & & & \\
\hline TDS, mg/L & & 26.5 & 24.5 & 25 & & 6.6 & 26.9 & 1000 & \\
\hline
\end{tabular}

Table 2: Physiochemical Parameters for River Irigu

$1^{\text {st }}$ Sampling-January, 2013

\begin{tabular}{|c|c|c|c|c|c|c|}
\hline \multirow{2}{*}{ Parameters } & \multicolumn{6}{|c|}{ Sampling stations } \\
\hline & & IU1 & IU2 & IL3 & IL4 & IL5 NEMA \\
\hline pH & 7.2 & 7.4 & 7.3 & 7.5 & 6.5 & $6.5-8.5$ \\
\hline
\end{tabular}

$\begin{array}{llllll}\mathbf{E C}, \mathbf{m S} & 0.06 & 0.06 & 0.06 & 0.06 & 0.06\end{array}$

$\begin{array}{lllllll}\text { TDS, } \mathbf{m g} / \mathbf{L} & 22.9 & 23.5 & 23.2 & 22.1 & 22.2 & 1000\end{array}$

\section{$2^{\text {nd }}$ Sampling-February 2013 \\ Physiochemical}

\begin{tabular}{|c|c|c|c|c|c|}
\hline \multirow{2}{*}{ Parameters } & \multicolumn{5}{|l|}{ Sampling stations } \\
\hline & NU1 NU2 & NL3 & NL4 & NL5 & NEMA \\
\hline
\end{tabular}

\begin{tabular}{lllllll}
\hline $\mathbf{p H}$ & 6.7 & 6.2 & 6.4 & 6.5 & 6.5 & $6.5-8.5$
\end{tabular}

\begin{tabular}{llllll}
\hline $\mathbf{E C}, \mathbf{m S}$ & 0.53 & 0.47 & 0.79 & 0.54 & 0.53
\end{tabular}

\begin{tabular}{lllllll}
\hline TDS, mg/L & 15.9 & 14.2 & 15.8 & 15.8 & 16.3 & 1000
\end{tabular}




\begin{tabular}{lcccccc}
\hline \multirow{2}{*}{ Physiochemical } & \multicolumn{7}{c}{ Sampling stations } \\
\cline { 2 - 7 } & \multicolumn{7}{c}{ IU1 } & IU2 & IL3 & IL4 & IL5 & NEMA \\
\hline pH & 6.2 & 7.2 & 6.3 & 7 & 7.2 & $6.5-8.5$ \\
\hline EC, $\mathbf{~ m S ~}$ & 0.4 & 0.42 & 0.66 & 0.6 & 0.5 & \\
\hline TDS, $\mathbf{~ m g / L ~}$ & 11.6 & 11.8 & 12.6 & 12.8 & 13.2 & 1000 \\
\hline
\end{tabular}

NB: TDS $=$ Total Dissolved Solids

The $\mathrm{pH}$ value of water is an important indication of its quality and it is dependent on the carbon dioxide, carbonate-bicarbonate equilibrium. Acid-base reactions are important in ground water because of their influence on $\mathrm{pH}$ and the ion chemistry [Abida et al, 2009]. The $\mathrm{pH}$ value in the study areas varied between 6.2 and 7.5. The $\mathrm{pH}$ value of 7.5 to 8.0 usually indicates the presence of calcium and magnesium. Electrical conductivity is a useful parameter of water quality for indicting salinity hazards [Abida et al, 2009]. Electrical conductivity of Rivers Naka and Irigu was found to be varied from $0.06 \mathrm{mS}$ to $0.79 \mathrm{mS}$.

Table 2: Concentration of $\mathrm{Pb}, \mathrm{Cd}$ and $\mathrm{As}$ in Water Samples of river Naka

\begin{tabular}{|c|l|l|l|c|}
\hline \multicolumn{1}{|l|}{$\mathbf{1}^{\text {st }}$ Sampling-January $\mathbf{2 0 1 3}$} & \multicolumn{1}{c|}{ Cd } & \multicolumn{1}{c|}{ As } & Hg \\
\hline \multicolumn{7}{|c|}{ Sample No. } & \multicolumn{1}{|c|}{ Pb } & $0.0233 \pm 0.979$ & BDL \\
\hline NU1 & $0.421 \pm 0.064$ & $0.103 \pm 0.0036$ & $0.0287 \pm 0.92$ & BDL \\
\hline NU2 & $0.0537 \pm 0.103$ & $0.0808 \pm 0.0014$ & $0.0215 \pm 0.98$ & BDL \\
\hline NL3 & $0.671 \pm 0.078$ & $0.0598 \pm 0.0159$ & $0.0252 \pm 0.52$ & BDL \\
\hline NL4 & $0.671 \pm 0.14$ & $0.0832 \pm 0.006$ & $0.0337 \pm 0.55$ & BDL \\
\hline NL5 & $0.233 \pm 0.103$ & $0.0686 \pm 0.006$ & 0.03 & 0.001 \\
\hline NEMA & 0.01 & 0.003 & 0.01 & 0.001 \\
\hline WHO & 0.01 & 0.005 & 0.05 & \\
\hline
\end{tabular}

Table 2: Concentration of $\mathrm{Pb}, \mathrm{Cd}$ and $\mathrm{As}$ in Water Samples of river Irigu

\begin{tabular}{|c|l|c|c|c|}
\hline \multicolumn{5}{|l|}{$\mathbf{1}^{\text {st }}$ Sampling-January 2013} \\
\hline Sample No. & \multicolumn{1}{|c|}{ Pb } & Cd & As & Hg \\
\hline IU1 & $0.765 \pm 0.782$ & $0.24 \pm 0.0084$ & $0.98 \pm 0.0287$ & BDL \\
\hline IU2 & $0.473 \pm 0.0642$ & $0.0861 \pm 0.0059$ & $0.0287 \pm 0.922$ & BDL \\
\hline IL3 & $0.452 \pm 0.0531$ & $0.0365 \pm 0.0012$ & $0.0205 \pm 0.602$ & BDL \\
\hline IL4 & $0.202 \pm 0.053$ & $0.035 \pm 0.0006$ & $0.0245 \pm 0.715$ & BDL \\
\hline IL5 & $0.141 \pm 0.0545$ & BDL & $0.0337 \pm 0.549$ & BDL \\
\hline NEMA & 0.01 & 0.003 & 0.01 & 0.001 \\
\hline WHO & 0.01 & 0.005 & 0.05 & 0.001 \\
\hline
\end{tabular}

The results were then presented in bar graphs in order to view variation of analytes downstream and between the first and second sampling. These are shown below:

Fig 1: Bar Graph for Lead, Cadmium and Arsenic ( $1^{\text {st }}$ Sampling)

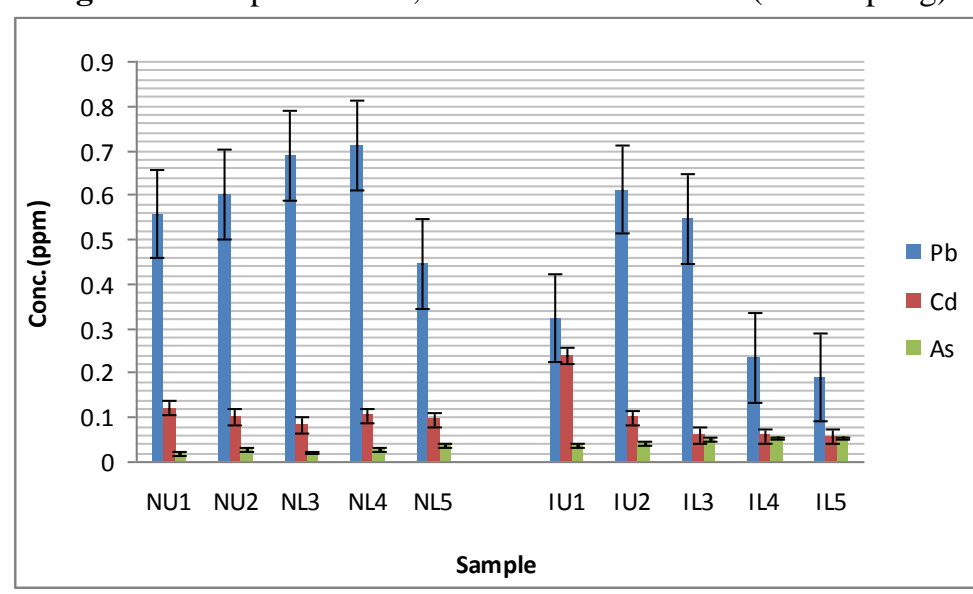


Fig 2: Bar Graph Lead, Cadmium and Arsenic ( $2^{\text {nd }}$ Sampling)

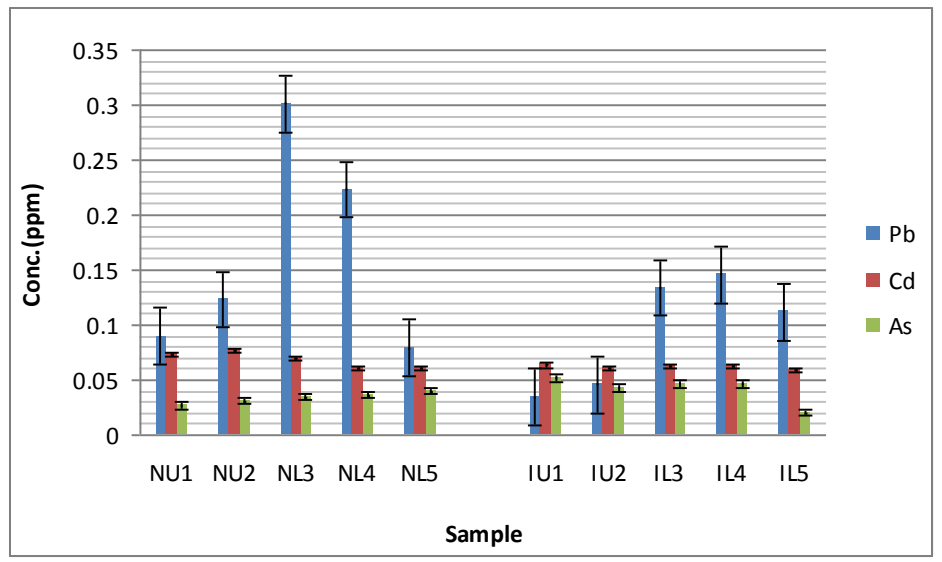

Table 3: Concentration of $\mathrm{NO}_{3}{ }^{-}$and $\mathrm{PO}_{4}{ }^{3-}$ in water samples in River Naka

\begin{tabular}{|c|c|c|c|c|}
\hline \multicolumn{2}{|c|}{$\mathbf{1}^{\text {st }}$ Sampling-January 2013} & $2^{\text {nd }}$ Sampling-February 2013 \\
\hline Sample No. & Nitrate & Phosphate & Nitrate & Phosphate \\
\hline NU1 & $1.884 \pm 0.049$ & $9.605 \pm 0.062$ & $2.44 \pm 0.048$ & $8.66 \pm 0.572$ \\
\hline NU2 & $2.079 \pm 0.049$ & $9.675 \pm 0.124$ & $2.23 \pm 0.082$ & $8.66 \pm 0.189$ \\
\hline NL3 & $2.196 \pm 0.037$ & $9.625 \pm 0.258$ & $2.29 \pm 0.06$ & $8.87 \pm 0189$ \\
\hline NL4 & $2.199 \pm 0.051$ & $8.917 \pm 0.124$ & $2.65 \pm 0.033$ & $8.36 \pm 0.258$ \\
\hline NL5 & $2.689 \pm 0.102$ & $9.524 \pm 0.124$ & $2.65 \pm 0.066$ & $8.61 \pm 0.327$ \\
\hline NEMA & 50 & 2.2 & 50 & 2.2 \\
\hline WHO & 45 & & 45 & \\
\hline
\end{tabular}

Table 3: Concentration of $\mathrm{NO}_{3}{ }^{-}$and $\mathrm{PO}_{4}{ }^{3-}$ in water samples in River Naka

\begin{tabular}{|c|c|c|c|c|}
\hline IU1 & $1.977 \pm 0.054$ & $10.03 \pm 0.189$ & $2.69 \pm 0.062$ & $9.78 \pm 0.189$ \\
\hline IU2 & $2.303 \pm 0.116$ & $10.33 \pm 0.189$ & $2.76 \pm 0.029$ & $8.56 \pm 0.348$ \\
\hline IL3 & $1.904 \pm 0.085$ & $9.928 \pm 0.501$ & $2.91 \pm 0.082$ & $8.31 \pm 0.429$ \\
\hline IL4 & $2.619 \pm 0.151$ & $9.979 \pm 0.447$ & $2.6 \pm 0.65$ & $9.94 \pm 0.406$ \\
\hline IL5 & $2.306 \pm 0.135$ & $10.13 \pm 0.372$ & $2.63 \pm 0.08$ & $8.92 \pm 0.124$ \\
\hline NEMA & 50 & 2.2 & 50 & 2.2 \\
\hline WHO & 45 & & 45 & \\
\hline
\end{tabular}

Figure 3: Bar Graph for Nitrate and Phosphate $1^{\text {st }}$ Sampling

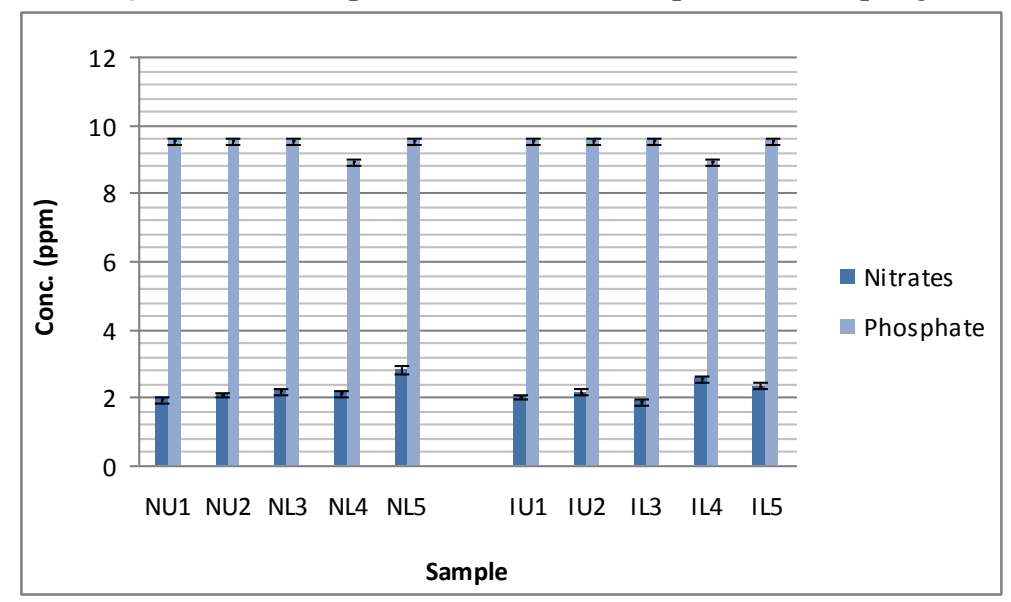


Figure 4: Bar Graph for Nitrates and Phosphates $2^{\text {nd }}$ Sampling

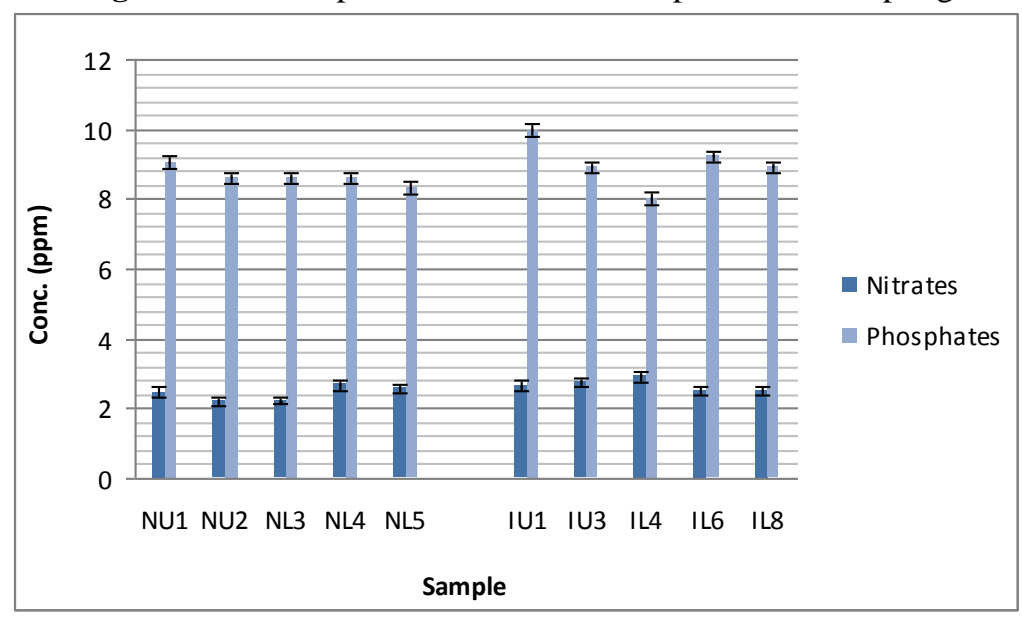

\section{Discussion:}

From the findings of this research, it was found that the concentration of lead, cadmium and arsenic varied downstream in both rivers Naka and Irigu. Lead had the highest concentration followed by cadmium and finally arsenic. On comparison with the permissible levels of lead, cadmium and arsenic in drinking water according to KEBS and WHO standards, the three were found to be far much beyond these values (Table 2.1). Lead had the highest concentration, with a range of $0.0537 \pm 0.103 \mathrm{ppm}$ to $0.765 \pm 0.782 \mathrm{ppm}$ in the first sampling period (January) for the two rivers. In the second sampling (February), it had a range of $0.0354 \pm$ $0.0146 \mathrm{ppm}$ to $0.285 \pm 0.015 \mathrm{ppm}$ in both rivers. This shows a decrease in concentration from the first sampling. KEBS and WHO Standards has a value $0.001 \mathrm{ppm}$. This high lead concentration can be attributed to the effluents from Chuka Town that empties into River Naka. These may be containing lead arising from petrol stations, soldering, plumbing, and also from exhausts of vehicles along the road. Corrosion from the metal linings of the pipes through which coffee berries pass may be the source of high levels of lead in River Irigu.

Cadmium was relatively lower than lead but still higher than the KEBS and WHO permissible levels of $0.003 \mathrm{ppm}$ and $0.005 \mathrm{ppm}$ respectively (Table 2.1 ). In both rivers the ranges were $0.035 \pm 0.0006$ to $0.24 \pm$ $0.0084 \mathrm{ppm}$ for the first sampling and $0.036 \pm 0.0007 \mathrm{ppm}$ to $0.054 \pm 0.0119 \mathrm{ppm}$ for the second sampling. Cadmium is usually associated with zinc in its occurrence. Hence corrosion of galvanized pipes and tanks can add cadmium to water which may be a contributing factor to the high levels of cadmium.

Arsenic was also found to be beyond the stipulated value of $0.01 \mathrm{ppm}$ according to KEBS, but below that given by WHO of $0.05 \mathrm{ppm}$. However, it had the lowest concentration in comparison to lead and cadmium, with a concentration in the range of $0.0205 \pm 0.602 \mathrm{ppm}$ to $0.0337 \pm 0.55 \mathrm{ppm}$ in the first sampling and $0.0195 \pm$ $0.419 \mathrm{ppm}$ in the second sampling. Mercury was below the detection limit, (BDL) in both rivers. A slight increase in concentration up to sampling point three in River Naka can be attributed to the effect of direct entrance of waste from Chuka Town at this point. On the other hand, the level of phosphate was extremely high at some points, and far beyond the recommended level. Nitrate-nitrogen was found to be far much below the recommended value of $50 \mathrm{mg} / \mathrm{L}$. Both phosphate and nitrate concentration were found to be relatively constant down the two rivers under study. All The physical parameters, i.e. total dissolved solids (TDS), electrical conductivity and $\mathrm{pH}$, (Table 4.5) were all found to be within the recommended values for drinking water by KEBS and WHO.

\section{Acknowledgement}

We would like to thank the Kenya Bureau of Standards (KEBS) for their assistance during the study. We are also grateful to JKUAT Chemistry and Food Science Departments for allowing us to use their facilities.

\section{Refferences}

[1]. Abida, B., Ramaiah, M., Harikrishna, S., Irfanulla, K., and Veena, K. (2009). "Heavy Metal Pollution and Chemical Profile of Cauvery River Water", E-Journal of Chemistry 6(1), 47-52.

[2]. Abida, B., Harikrishna, S., and Irfanulla, K. (2009). "Analysis of Heavy Metals in Water, Sediments and Fish samples of Madivala Lakes of Bangalore, Karnata", International Journal of ChemTech Research 1 (2), 245-249.

[3]. Adams, S. M. (2001). "Biomarker/bioindicator response profiles of organisms can help differentiate between sources of anthropogenic stressors in aquatic ecosystems", Biomarkers, 6:33-44

[4]. Alcamo, E. I. (2001). "Fundamentals of Micro-biology", 6th Edition, Page 788-790, 792.

[5]. Bellos, D., Sawidis, T., and Tsekos, I. (2004). "Nutrient chemistry of River Pinios (Thessalia, Greece)", Environ. Int. 30:105-115.

[6]. Boari, G., Mancini, I. M., and Trulli, E. (1997). “Technologies for water treatment”, Option mediterraneennes, 31:261-287. 
[7]. Bricker, O. P., and Jones, B. F. (1995). "Main factors affecting the composition of natural waters, In: Salbu B, Steines E (eds). Trace Metals in Natural Waters", CRC Press, pp. 1-19.

[8]. Bunce, N. J. (1994). "Environmental Chemistry", Wuerz publishing Ltd., $2^{\text {nd }}$ Edition, Page 199-224.

[9]. Carl, C. P. (1975). "Metal and Elemental Nutrients", Keats publishing Inc. Connecticut, page 312.

[10]. Clair, N. S., and McCarty, P. L. (1978). "Chemistry for Environmental Engineers", McGraw-Hill, Inc., (McGraw-Hill Series in Water Resources and Environmental Engineering). $3^{\text {rd }}$ Edition, page 482-487.

[11]. Daniel, L. (1998). "Microbiology", WCB/McGraw-Hill., $2^{\text {nd }}$ Edition, page 586-589.

[12]. Edorh, P. (2007). "Heavy metal action", TWAS Newsletter. 19(2):42-45.

[13]. Jackson, R. B., Carpenter, S. R., Dahm, C. N., McKnight, D. M., Naiman, R. J., Postel, S.L., and Running, S. W. (2001). "Water in a Changing World, Issues in ecology”, Ecological Society of America, Washington, DC, 9: 2-16.

[14]. Markich, S. J., and Brown, P. L. (1998). "Relative importance of natural and anthropogenic influences on the fresh surface water chemistry of the Hawkesbury-Nepean River, south-eastern Australia", Sci. Total Environ. 217:201-230.

[15]. Olatunji, O. S., and Osibanjo, O. (2012). "Determination of selected heavy metals in inland fresh water of lower River Niger drainage in North Central Nigeria", African Journal of Environmental Science and Technology, 6(10), 403-408. 